\title{
Do neurosurgeons receive more patient complaints than other physicians? Describing who is most at risk and how we can improve
}

\author{
${ }^{*}$ Robert J. Dambrino IV, MD, ${ }^{1}$ Scott L. Zuckerman, MD, MPH, ${ }^{1}$ Bradley S. Guidry, BS, ${ }^{2}$ \\ Henry J. Domenico, MS, ${ }^{3}$ Reid C. Thompson, MD, ${ }^{1}$ Mitchell B. Galloway, MS, ${ }^{4}$ \\ James W. Pichert, PhD, ${ }^{4}$ and William O. Cooper, MD, MPH ${ }^{4,5}$
}

${ }^{1}$ Department of Neurological Surgery, ${ }^{2}$ Vanderbilt University School of Medicine, ${ }^{3}$ Department of Biostatistics, ${ }^{4}$ Center for Patient and Professional Advocacy, and ${ }^{5}$ Department of Pediatrics, Vanderbilt University Medical Center, Nashville, Tennessee

\begin{abstract}
OBJECTIVE The number of unsolicited patient complaints (UPCs) about surgeons correlates with surgical complications and malpractice claims. Using a large, national patient complaint database, the authors sought to do the following: 1) compare the rates of UPCs for neurosurgeons to those for other physicians, 2) analyze the risk of UPCs with individual neurosurgeon characteristics, and 3) describe the types of UPCs made about neurosurgeons.
\end{abstract}

METHODS Patient and family complaint reports among 36,265 physicians, including 423 neurosurgeons, 8292 other surgeons, and 27,550 nonsurgeons who practiced at 33 medical centers (22 academic and 11 regional) from January 1 , 2014, to December 31, 2017, were coded with a previously validated Patient Advocacy Reporting System (PARS) algorithm.

RESULTS Among 423 neurosurgeons, $93 \%$ were male, and most $(71 \%)$ practiced in academic medical centers. Neurosurgical subspecialties included general practice $(25 \%)$, spine $(25 \%)$, tumor $(16 \%)$, vascular $(13 \%)$, functional $(10 \%)$, and pediatrics (10\%). Neurosurgeons had more average total UPCs per physician $(8.68 ; 95 \% \mathrm{Cl} 7.68-9.67)$ than nonsurgeons $(3.40 ; 95 \% \mathrm{Cl} 3.33-3.47)$ and other surgeons (5.01; $95 \% \mathrm{Cl} 4.85-5.17 ; \mathrm{p}<0.001)$. In addition, a significantly higher percentage of neurosurgeons received at least one UPC $(71.6 \% ; 95 \% \mathrm{Cl} 67.3 \%-75.9 \%)$ than did nonsurgeons (50.2\%; $95 \% \mathrm{Cl} 49.6 \%-50.8 \%$ ) and other surgeons (58.2\%; $95 \% \mathrm{Cl} 57.1 \%-59.3 \% ; \mathrm{p}<0.001)$. Factors most associated with increased average UPCs were younger age, measured as median medical school graduation year (1990.5 in the 0-UPC group vs 1993 in the 14+-UPC group, $p=0.009$ ) and spine subspecialty (13.4 mean UPCs in spine vs 7.9 mean UPCs in other specialties, $95 \% \mathrm{Cl} 2.3-8.5, p<0.001)$. No difference in complaints was seen in those who graduated from non-US versus US medical schools $(p=0.605)$. The most common complaint types were related to issues surrounding care and treatment, communication, and accessibility, each of which was significantly more common for neurosurgeons than other surgical specialties $(p<0.001)$.

CONCLUSIONS Neurosurgeons were more likely to generate UPCs than other surgical specialties, and almost 3 out of 4 neurosurgeons $(71.6 \%)$ had at least one UPC during the study period. Prior studies have shown that feedback to physicians about behavior can result in fewer UPCs. These results suggest that neurosurgeons have opportunities to reduce complaints and potentially improve the overall quality of care delivered.

https://thejns.org/doi/abs/10.3171/2020.4.JNS20870

KEYWORDS patient complaints; malpractice; surgical complications

$\mathrm{I}$ $\mathrm{N}$ the field of neurosurgery, achieving excellence in patient care, maximizing patient safety, and ensuring a positive hospital experience are shared goals of surgeons, patients, departments, and healthcare organizations. Among all medical specialties, neurosurgery has the highest risk for litigation. ${ }^{1,2}$ Neurosurgeons also have the highest annual probability of facing malpractice claims; $19.1 \%$ experience at least 1 claim per year, with a mean indemnity payment of $\$ 344,811 .^{3}$ Nahed et al..$^{4}$ surveyed 1028 neurosurgeons and found that $64 \%$ considered malpractice premiums a "major" or "extreme" burden, causing $45 \%$ of respondents to eliminate high-risk procedures due

ABBREVIATIONS CORS $=$ Co-worker Observation Reporting System; CPPA = Vanderbilt Center for Patient and Professional Advocacy; PARS $=$ Patient Advocacy Reporting System; UPC = unsolicited patient complaint.

SUBMITTED March 23, 2020. ACCEPTED April 28, 2020.

INCLUDE WHEN CITING Published online July 31, 2020; DOI: 10.3171/2020.4.JNS20870.

${ }^{*}$ R.J.D. and S.L.Z. contributed equally to this work. 
to liability concerns. ${ }^{4}$ In a survey of more than 7000 surgeons, both depression and burnout were independently associated with a recent malpractice suit, and those with a recent suit were less satisfied with their career and less likely to recommend a career in medicine to their children. ${ }^{5}$ Finding ways to decrease litigation risk is of interest to all practitioners involved in delivering complex neurosurgical care.

Unsolicited patient complaints (UPCs), received by healthcare systems when healthcare expectations are not met or exceeded, have been shown to independently predict risk management activity, malpractice claims, and postoperative complications. ${ }^{6}$ The small percentage of physicians who are associated with disproportionate shares of complaints are the same physicians who account for up to $50 \%$ of malpractice claim-related losses for health systems. ${ }^{7,8}$ Thus, addressing interactions and events that result in UPCs may decrease litigation risk, mitigate postoperative complications, and improve the quality of care delivered. ${ }^{6,9}$ Given the complex clinical, psychosocial, surgical, and postoperative nature of neurosurgical care, increasing our understanding of the factors that contribute to UPCs is particularly important.

The objective of our study was to identify specific patterns of UPCs among neurosurgeons. Using a large, national patient complaint database, we aimed to do the following: 1) compare the distribution and rate of UPCs for neurosurgeons to those for other physicians, 2) analyze differences in risk of UPCs by individual neurosurgeon factors, and 3) describe the type of UPCs made about neurosurgeons.

\section{Methods}

\section{Design and Data Sources}

We conducted a retrospective cohort study comparing neurosurgeons to other surgical specialists and nonsurgeons. The study period was January 1, 2014, through December 31,2017. The study used data from the Vanderbilt Center for Patient and Professional Advocacy (CPPA), which maintains an electronic database housing patient complaint data for more than 60,000 US physicians credentialed at participating healthcare institutions across the country. The CPPA uses its Patient Advocacy Reporting System (PARS) in collaboration with hospitals and medical groups to identify and intervene with affiliated physicians who have an increased number of UPCs. The CPPA promotes group and self-regulation by providing peer-comparative feedback for physicians whose volume of complaints shows them to be outliers on a local and national level. Such feedback has been shown to reduce the risks of UPCs in a large majority of involved professionals..$^{10}$

\section{Study Population}

Physicians in all medical and surgical specialties registered within the PARS database with active credentials during the study period were included in the final cohort. A 4-year audit period (with annual data points) was used to permit identification of practice patterns. Resident physicians and fellows were excluded from the analysis as well as physicians without 4 consecutive years of UPC data. Neurosurgeons, other surgeons, and nonsurgeons were identified from credentialing files from each site. Non-neurosurgeon surgeons included physicians from the following specialties: obstetrics and gynecology, orthopedics, ophthalmology, general surgery (transplant, colorectal, oncology, trauma), otolaryngology, urology, plastic surgery, cardiothoracic, and vascular.

\section{Measures}

The outcome of interest was UPCs. The CPPA processed all UPCs and characterized them according to 6 categories: 1) care and treatment, 2) communication, 3) humanistic concern for patient, 4) accessibility, 5) environment, and 6) billing issues. ${ }^{10}$ Individual neurosurgeon factors included sex, age (measured by medical school graduation year) ${ }_{1}^{11}$ foreign medical school graduate (yes or no), academic practice (yes or no), and subspecialty. Neurosurgical subspecialties were identified through manual review of each healthcare organization's website and included functional, general, pediatric, spine, tumor, or vascular according to previously described methods..$^{11}$ To have a subspecialty of pediatric or vascular, evidence of fellowship training was required.

\section{Statistical Analyses}

Descriptive statistics characterizing the study population were reported at the physician level. Continuous variables were reported as medians and interquartile ranges. Categorical variables were reported as frequencies and proportions. The average totals of UPCs among neurosurgeons were compared by sex, medical school graduation year, medical school location, practice setting, geographic region, and subspecialty. These UPCs were then compared between neurosurgeons, other surgeons, and nonsurgeons. Average total complaints were reported for each group with a 95\% confidence interval (CI). A Wilcoxon ranksum test was used to compare total complaints between 2 groups, and a Kruskal-Wallis rank-sum test was used for 3 or more groups. Two-sided $p$ values of less than 0.05 were considered statistically significant. All statistical analyses were performed with $\mathrm{R}$ statistical software version 3.5.1 (R Foundation).

\section{Ethical Considerations}

The confidentiality of individual physician demographic information linked to UPC data was the greatest risk of this study. These data were deidentified prior to study initiation by a third party not involved in the conduct of the study. To protect confidentiality, the names of neurosurgeons were used to obtain demographic data; however, the UPC data were kept separate. A third party (computer programmer who did not participate in the analysis) linked demographic and subspecialty data to the patient complaint information. The programmer then deidentified the data sets used for analysis; these data sets could not be linked back to an individual. The Vanderbilt Institutional Review Board approved the study as nonhuman subjects research and waived the consent requirement (Vanderbilt IRB no. 171876). 
TABLE 1. Neurosurgeon demographics

\begin{tabular}{ll}
\hline \multicolumn{1}{c}{ Variable } & \multicolumn{1}{c}{ Value } \\
\hline Total no. of neurosugeons & 423 \\
\hline Male sex $(n=378)$ & $352(93 \%)$ \\
\hline $\begin{array}{l}\text { Med school graduation yr, median }(\mathrm{Q} 1-\mathrm{Q} 3) \\
(\mathrm{n}=421)\end{array}$ & $1992(1981-2001)$ \\
\hline Neurosurgical subspecialty $(\mathrm{n}=378)$ & \\
\hline Functional & $39(10 \%)$ \\
\hline General & $96(25 \%)$ \\
\hline Pediatric & $39(10 \%)$ \\
\hline Spine & $93(25 \%)$ \\
\hline Tumor & $62(16 \%)$ \\
\hline Vascular & $49(13 \%)$ \\
\hline Non-US med school $(\mathrm{n}=378)$ & $61(16 \%)$ \\
\hline Non-US residency $(\mathrm{n}=378)$ & $28(7 \%)$ \\
\hline Academic $(\mathrm{n}=423)$ & $301(71 \%)$ \\
\hline Region $(\mathrm{n}=378)$ & \\
\hline East & $59(16 \%)$ \\
\hline Midwest & $116(31 \%)$ \\
\hline South & $56(15 \%)$ \\
\hline West & $147(39 \%)$ \\
\hline
\end{tabular}

Med $=$ medical; $Q=$ quartile.

Values are presented as number of patients (\%) unless otherwise indicated.

\section{Results}

\section{Characteristics of Study Participants}

A total of 36,265 physicians, including 423 neurosurgeons, 8292 other surgeons, and 27,550 nonsurgeons were included in the final analysis. A greater proportion (93\%) of neurosurgeons were male (Table 1). All subspecialties were represented, with general practice $(25 \%)$ and spine $(25 \%)$ being the most common, followed by tumor $(16 \%)$ and vascular (13\%). The majority of neurosurgeons practiced in an academic medical center setting (71\%). A minority graduated from medical schools outside the US $(16 \%)$, and even fewer completed residency training outside the US (7\%).

\section{Unsolicited Patient Complaints}

Neurosurgeons had higher rates of mean total complaints per physician $(8.68$; 95\% CI 7.68-9.67) than nonsurgeons $(3.40 ; 95 \%$ CI 3.33-3.47) and other surgeons (5.01; 95\% CI 4.85-5.17) ( p < 0.001) (Fig. 1). Neurosurgeons also had a significantly higher proportion of physicians with a UPC (71.6\%; 95\% CI 67.3\%-75.9\%) compared to nonsurgeons $(50.2 \%$; $95 \%$ CI $49.6 \%-50.8 \%)$ and other surgeons $(58.2 \%$; 95\% CI 57.1\%-59.3\%) (p < 0.001) (Fig. 2). Fifty percent of the total complaints were caused by $17.7 \%$ of neurosurgeons.

\section{Factors Associated With Increased Numbers of Unsolicited Patient Complaints}

Neurosurgeons were divided into quartiles of total complaints, and demographic variables were compared

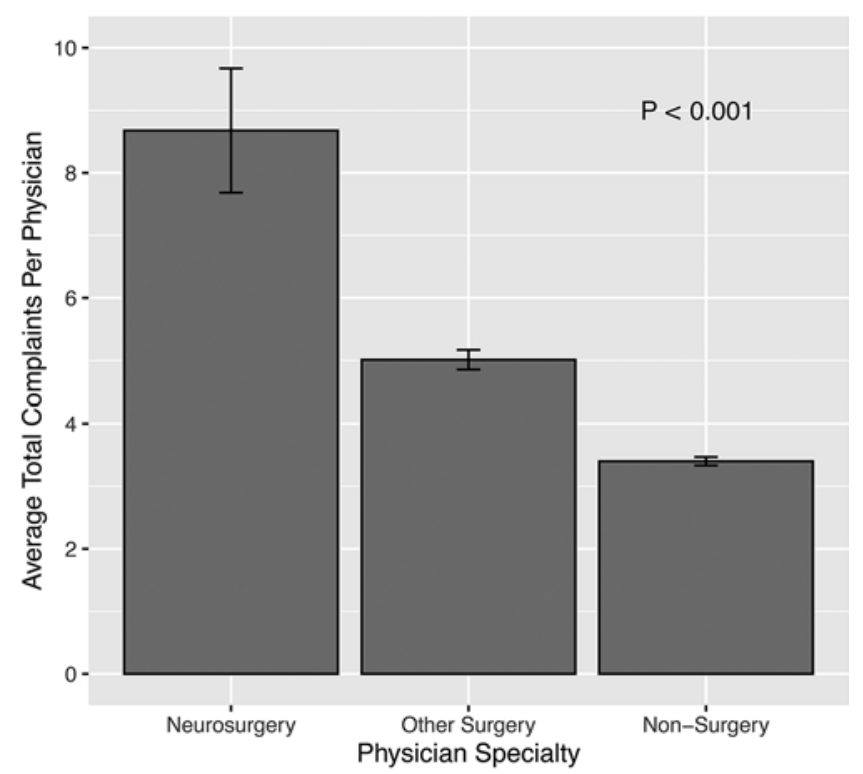

FIG. 1. Comparison of average total UPCs by specialty.

between groups (Table 2). Significant differences were associated with neurosurgeon age (by medical school graduation year) and subspecialty. Younger neurosurgeons (later medical school graduation years) were seen in the upper 2 quartiles of UPCs $(p<0.001)$. The spine subspecialty had the highest percentage of neurosurgeons in the upper quartile of UPCs $(\mathrm{p}<0.001)$. No difference in complaints was seen in those who graduated from non-US versus US medical schools ( $16 \%$ in the 0 -complaint category vs $16 \%$ in the $14+$-complaint category, $\mathrm{p}=0.605$ ).

\section{Types of Complaints}

Compared to other surgical specialties, neurosurgeons had higher average total complaints (8.68 vs $5.01,95 \% \mathrm{CI}$ 2.66-4.67, $\mathrm{p}<0.001$ ) and complaints in the categories of care and treatment (3.92 vs 2.37, 95\% CI 1.10-1.996, p < $0.001)$, communication (2.12 vs $1.00,95 \%$ CI $0.87-1.38, \mathrm{p}$

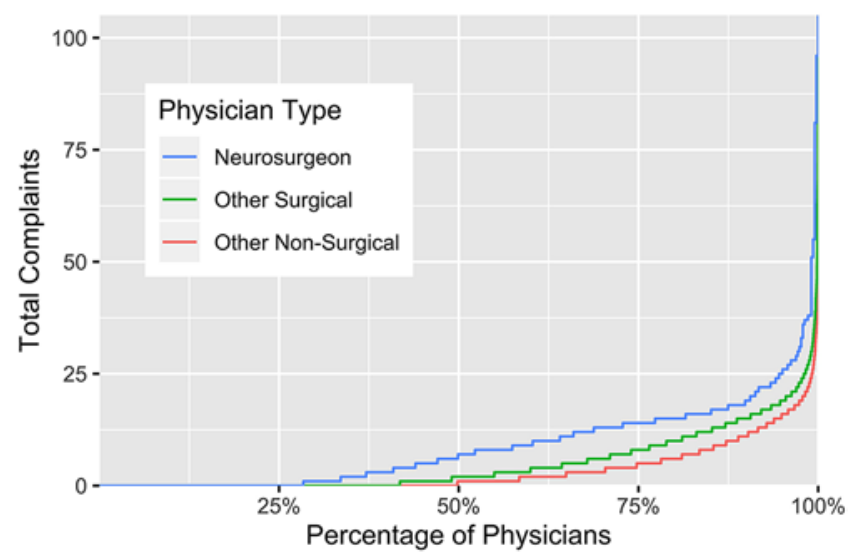

FIG. 2. Comparison of distribution of UPCs for different physician groups. Figure is available in color online only. 
TABLE 2. Distribution of complaints according to neurosurgeon demographics from 2014 to 2017

\begin{tabular}{|c|c|c|c|c|c|c|}
\hline Neurosurgeon Characteristics & Total No. & 0 UPCs $(n=120)$ & $1-6$ UPCs $(n=91)$ & $7-13$ UPCs $(n=97)$ & $14+$ UPCs $(n=115)$ & p Value \\
\hline Male sex $(n=378)$ & 378 & $0.89(93)$ & $0.95(69)$ & $0.95(83)$ & $0.94(107)$ & $0.355^{*}$ \\
\hline $\begin{array}{l}\text { Med school graduation yr, } \\
\text { median (Q1-Q3) }(n=421)\end{array}$ & 421 & $\begin{array}{c}1990.5 \\
(1979.0-2001.0)\end{array}$ & $\begin{array}{c}1987.0 \\
(1969.5-2001.0)\end{array}$ & $\begin{array}{c}1994.0 \\
(1984.0-2003.0)\end{array}$ & $\begin{array}{c}1993.0 \\
(1984.5-2001.5)\end{array}$ & $0.009^{* *}$ \\
\hline Non-US med school & 378 & $0.16(17)$ & $0.21(15)$ & $0.13(11)$ & $0.16(18)$ & $0.605^{*}$ \\
\hline Academic & 423 & $0.69(83)$ & $0.74(67)$ & $0.73(71)$ & $0.70(80)$ & $0.84^{*}$ \\
\hline $\begin{array}{l}\text { Distribution of complaint } \\
\text { category by subspecialty }\end{array}$ & & & & & & $<0.001^{* A}$ \\
\hline Functional & 39 & $0.26(10)$ & $0.26(10)$ & $0.23(9)$ & $0.26(10)$ & 0.9945 \\
\hline General & 96 & $0.48(46)$ & $0.18(17)$ & $0.14(13)$ & $0.21(20)$ & $<0.001^{B}$ \\
\hline Pediatric & 39 & $0.33(13)$ & $0.23(9)$ & $0.18(7)$ & $0.26(10)$ & $0.5885^{\circ}$ \\
\hline Spine & 93 & $0.17(16)$ & $0.10(9)$ & $0.28(26)$ & $0.45(42)$ & $<0.001^{B}$ \\
\hline Tumor & 62 & $0.15(9)$ & $0.10(6)$ & $0.37(23)$ & $0.39(24)$ & 0.0008 \\
\hline Academic & 50 & $0.10(5)$ & $0.12(6)$ & $0.4(20)$ & $0.38(19)$ & $0.001^{B}$ \\
\hline Nonacademic & 12 & $0.33(4)$ & $0.0(0)$ & $0.25(3)$ & $0.42(5)$ & $0.198^{B}$ \\
\hline Vascular & 49 & $0.2(10)$ & $0.45(22)$ & $0.18(9)$ & $0.16(8)$ & $0.015^{B}$ \\
\hline
\end{tabular}

Values are presented as proportion (number of patients) unless otherwise indicated. ${ }^{*}$ Pearson chi-square test; ${ }^{* *}$ Kruskal-Wallis test; $A=$ test for association between subspecialty and complaint category; B = chi-square goodness of fit test for equal proportion of physicians within each complaint category by subspecialty.

$<0.001)$, concern for patient $(0.86$ vs $0.53,95 \%$ CI $0.14-$ $0.53, \mathrm{p}<0.001)$, and accessibility $(1.46$ vs $0.81,95 \% \mathrm{CI}$ $0.43-0.87, \mathrm{p}<0.001)($ Table 3$)$.

Patients expressed a range of care and treatment dissatisfactions, and many complaints were not directly related to the surgical procedure or outcomes (Table 4). Complaints about care and treatment often arose related to postoperative care in both inpatient and outpatient settings ("They [the neurosurgeons] feel like the surgery is done and they can just walk away"). Communication concerns encompassed a range of behaviors, including being surprised by new information ("We were never informed that my wife will be on blood thinners for the rest of her life") or a perceived lack of communication ("After speaking to me about surgery, there has been zero communication rendered"). Accessibility complaints often arose from patients' expectations that they would always see their attending surgeon ("I didn't even see the doctor and only saw a resident"). Complaints about showing concern for the patient related to a perceived lack of empathy or caring toward the patient ("Dr. ..was disengaged...rolled his eyes...his behavior was unprofessional and insensitive").

\section{Discussion}

In this large, national study of UPCs among 36,265 physicians, neurosurgeons received more UPCs than other surgeons, with almost 3 out of 4 neurosurgeons (71.6\%) receiving at least one UPC. Younger neurosurgeons and those with a spine subspecialty had an increased risk of complaints. The most common complaint types were related to care and treatment, communication, accessibility, and concern for patients.

\section{Neurosurgeons Compared to Others}

Neurosurgeons had an increased risk of complaints compared to other physicians and other surgeons. In previous studies of ophthalmologists, ${ }^{12}$ plastic surgeons, ${ }^{13}$ and

TABLE 3. Complaint totals and categories by physician type from 2014 to 2017

\begin{tabular}{lccc}
\hline \multicolumn{1}{c}{ Complaints } & Neurosurgeons $(n=423)$ & Other Surgeons $(n=8292)$ & $p$ Value \\
\hline All complaints & $8.68(7.68-9.67)$ & $5.01(4.85-5.17)$ & $<0.001^{*}$ \\
\hline Any complaint, yes/no ratio $(95 \% \mathrm{Cl})$ & $0.716(0.673-0.759)$ & $0.582(0.571-0.593)$ & $<0.001^{* *}$ \\
\hline Categories & & & \\
\hline Care and treatment & $3.92(3.48-4.36)$ & $2.37(2.29-2.44)$ & $<0.001^{*}$ \\
\hline Communication & $2.12(1.87-2.37)$ & $1.00(0.96-1.03)$ & $<0.001^{*}$ \\
\hline Concern for patient & $0.86(0.67-1.06)$ & $0.53(0.5-0.56)$ & $<0.001^{*}$ \\
\hline Accessibility & $1.46(1.24-1.68)$ & $0.81(0.78-0.85)$ & $<0.001^{*}$ \\
\hline Environment & $0.01(0.00-0.02)$ & $0.01(0.01-0.01)$ & $0.9956^{*}$ \\
\hline Billing & $0.31(0.25-0.37)$ & $0.30(0.28-0.31)$ & $0.3664^{*}$ \\
\hline
\end{tabular}

Values are presented as mean $(95 \% \mathrm{Cl})$ unless otherwise indicated. ${ }^{*}$ Wilcoxon test; **Pearson chi-square test. 
TABLE 4. Complaint categories, subcategories, and examples

\begin{tabular}{|c|c|c|}
\hline Complaint Category & Subcategory & Example \\
\hline \multirow[t]{5}{*}{$\begin{array}{l}\text { Care and treat- } \\
\text { ment }\end{array}$} & $\begin{array}{l}\text { Inpatient not sur- } \\
\text { gery related }\end{array}$ & "Did not receive Parkinson's medication and did not return to cognitive baseline given this delay." \\
\hline & $\begin{array}{l}\text { Outpatient not } \\
\text { surgery related }\end{array}$ & $\begin{array}{l}\text { "They are trying to place all the responsibility on my wife's primary care doctor ... They feel like the sur- } \\
\text { gery is done and they can just walk away." }\end{array}$ \\
\hline & Surgery related & $\begin{array}{l}\text { "Needed a second surgery } 4 \text { days later." } \\
\text { "Upset that husband still dealing with numbness in right leg and atrophy in right calf." } \\
\text { "The infection prolonged the period of recovery for my wife's back surgery." } \\
\text { "My wife had a discectomy procedure by another doctor and feels that it is Dr. ___'s fault she needed } \\
\text { surgery again." }\end{array}$ \\
\hline & Inpatient pain & "She didn't have pain medication when she woke up ... the doctor hadn't placed the order." \\
\hline & Discharge related & "Discharged too early and fell at home." \\
\hline \multirow[t]{5}{*}{ Communication } & $\begin{array}{l}\text { Surprised by new } \\
\text { information }\end{array}$ & $\begin{array}{l}\text { "We were never informed that my wife will be on blood thinners for the rest of her life." } \\
\text { "I did not know they were going to take a hip graft and put it in my neck ... all I knew was the nuts, screws, } \\
\text { and size of incision ... the anesthesiologist told me about the hip bone part ... I was very upset." }\end{array}$ \\
\hline & $\begin{array}{l}\text { Perceived with- } \\
\text { holding of } \\
\text { information }\end{array}$ & $\begin{array}{l}\text { "Dr. did not tell me the screw went through the spinal canal but said it was a little too far medial." } \\
\text { "The recovery is turning out to be much longer than expected ... with more realistic information, we may } \\
\text { have postponed surgery a few months or bypassed it totally given the nature of the recovery process." } \\
\text { "We never got a full explanation on why the single screw could not be taken out." }\end{array}$ \\
\hline & Outpatient delays & "I had my EMG done and we are now in a new year and I have not heard from anyone from his team." \\
\hline & $\begin{array}{l}\text { Inpatient team } \\
\text { communications }\end{array}$ & $\begin{array}{l}\text { "The oncology team consistently has issues communicating with the neurosurgery team ... I also received } \\
\text { very different opinions from various teams that made it difficult to trust the plan." }\end{array}$ \\
\hline & $\begin{array}{l}\text { Outpatient com- } \\
\text { munication }\end{array}$ & $\begin{array}{l}\text { "We have had issues communicating with the office and this has delayed my brother's surgery." } \\
\text { "After speaking to me about surgery, there has been zero communication rendered." }\end{array}$ \\
\hline \multirow[t]{2}{*}{ Accessibility } & $\begin{array}{l}\text { Seeing a trainee } \\
\text { or midlevel } \\
\text { provider instead } \\
\text { of the attending } \\
\text { surgeon }\end{array}$ & $\begin{array}{l}\text { "I had an appointment scheduled there yesterday ... I waited } 3 \text { hours and didn't even see the doctor and } \\
\text { only saw a resident." } \\
\text { "I have never met with Dr. } \\
\text { "I have called } 5 \text { or } 6 \text { times to try to get an appointment with him ... I don't want to see his students; I want } \\
\text { to see him ... All he seems to do is push me off to his residents, and I'm fed up." }\end{array}$ \\
\hline & $\begin{array}{l}\text { Wanting to speak } \\
\text { directly with } \\
\text { the attending } \\
\text { surgeon }\end{array}$ & $\begin{array}{l}\text { "Dr. ____ has not once called me back." } \\
\text { "I had an appointment scheduled there yesterday ... I waited } 3 \text { hours and didn't even see the doctor and } \\
\text { only saw a resident." } \\
\text { "I waited over a month to see Dr.____ for } 3 \text { minutes." }\end{array}$ \\
\hline $\begin{array}{l}\text { Concern for } \\
\text { patient }\end{array}$ & $\begin{array}{l}\text { Lack of empathy } \\
\text { or caring toward } \\
\text { the patient }\end{array}$ & $\begin{array}{l}\text { "Did not seem to be listening ... simply said that he didn't treat pain and started to walk away." } \\
\text { "Does he care about anyone or just fees? Heck with the current patient ... on with the next." } \\
\text { "He did apologize but jumped on being defensive, he seemed like he didn't care." } \\
\text { "He never even came in the room to acknowledge me ... he didn't think enough of me to show his face." } \\
\text { "Dr. _-_ displayed a cold demeanor, was disengaged ... rolled his eyes, and was tapping his finger, anx- } \\
\text { iously, on the desk and the wall ... his behavior was unprofessional and insensitive." } \\
\text { "He wasn't very pleasant ... when I first met him he told me to sit down and shut up or l'll call security ... } \\
\text { This man is a narcissist, and just plain mean." }\end{array}$ \\
\hline
\end{tabular}

dermatologists, ${ }^{13}$ all had decreased risks of UPCs compared to other surgeons, while trauma surgery ${ }^{14}$ and otolaryngology ${ }^{15}$ had increased UPC risks compared to other surgeons. These differences may reflect variations in the risks of surgical procedures performed by various specialties. In addition, although a minority of neurosurgeons accounted for most complaints, $71.6 \%$ had at least one UPC. This increased risk is in contrast to those of other surgical subspecialties that had significantly smaller proportions of those receiving at least 1 complaint-37\% of ophthalmologists, $51 \%$ of plastic surgeons, and $53 \%$ of urologists. It is possible that the increased risk of UPCs among neurosurgeons relative to other surgical specialties is related to the heterogeneity of practice and risk across the 6 neurosurgical subspecialties. However, similar numbers of subspecialty designations were reported in prior studies of UPCs across other surgical disciplines, including studies in otolaryngology (7 subspecialties) $)^{15}$ urology (9 subspecialties), ${ }^{16}$ and ophthalmology (12 subspecialties). ${ }^{11}$

\section{Individual Neurosurgeon Risk Factors}

Younger neurosurgeons and those with a spine subspecialty had increased risks of receiving UPCs. The 2 highest quartiles of complaints both had significantly younger surgeons than the 2 lowest quartiles. The same trend has been found among ophthalmologists, among whom sur- 
geons 31-40 years old had more than twice the risk of incurring a UPC than more senior ophthalmologists. ${ }^{11}$ While these results do not allow us to determine causation, several phenomena may be occurring. First, developing proficiency in a technical skill takes time, and the early years of honing that skillset require a learning curve. Second, mastering a new clinical system and learning how to provide excellent care within that system require experience. Complaints may arise as a new surgeon learns how to run an efficient clinic, manage a busy surgical day, and identify appropriate patient care resources and referrals. ${ }^{11}$ Third, younger neurosurgeons may be given lessexperienced support staff, who also require experience to become proficient in the outpatient setting. These results likely encompass a combination of behavioral, technical, and confidence issues that emerge as one begins a surgical practice. ${ }^{11}$ These findings are consistent with data showing that surgeons in their first 10 years of practice have the highest risk of malpractice claims, with the risk peaking for surgeons in their 40s. ${ }^{3}$

Spine surgeons, who treat a majority of elective problems dealing with pain, disability, and quality of life, were at a significantly increased risk of receiving UPCs. Few spine surgeons were immune to UPCs-only 17\% had zero complaints. Furthermore, of all subspecialties, spine surgeons had the highest percentage of neurosurgeons in the highest quartile of 14+ complaints, an interesting finding given that most spine surgery is elective and carries less risk of catastrophic complications than other neurosurgical subspecialties. For example, cranial operations have been shown to have a 2.6 times greater likelihood of having complications compared to spinal operations. ${ }^{17}$ The high rate of complaints among spine surgeons becomes increasingly relevant due to the associated litigation risk. Daniels et al. ${ }^{18}$ found that litigation costs among 234 spine-oriented malpractice cases ranged from $\$ 125,000$ to $\$ 9,000,000$. Factors associated with plaintiff rulings and settlements were catastrophic complications (death, ischemic brain injury, and spinal cord injury), delays in diagnosis, and postoperative complications. ${ }^{18}$

Procedures in higher-risk areas, such as vascular and tumor surgeries, for which operations have greater potential to result in permanent disability or death, had lower risks of UPCs compared to a more elective-based spine practice. A similarly decreased risk of legal claims after cranial surgery compared to spine surgery has also been noted. ${ }^{19}$ The decreased risk of UPCs among vascular and tumor surgeries may speak to the importance of preoperative expectations. For instance, brain tumor patients with a known or presumptive terminal diagnosis may be more grateful for care and accepting of risks given their poor prognosis. At the end of life, these patients may have an increased fear of abandonment, and thus look to their healthcare providers and surgeons for companionship and care. Interestingly, prior studies have shown that common diagnoses associated with brain tumor litigation were pituitary adenomas, acoustic neuromas, and meningiomas, which represent mostly benign, less emergent processes. ${ }^{20}$ Pituitary adenoma surgery may lead to visual deficits, and acoustic neuroma surgeries can lead to facial nerve impairments - both significant detriments to quality of life in nonterminal scenarios. Likewise, cerebrovascular surgeries are often lifesaving and emergent, which may lead to tempered expectations for patients and family members. In contrast to common spinal surgeries, where the goal of surgery is often to alleviate pain and improve quality of life as opposed to salvaging vital neurological functions or extending life, the findings of the present study suggest that spine surgeons may benefit by weighing communication of surgical expectations with patients' perceptions of what constitutes a successful surgical outcome. Seventeen percent of spine surgeons had no complaints, suggesting that it is possible to provide care for patients requiring the care of a spine surgeon without generating dissatisfaction.

Given the finding that more elective spine practices lead to more UPCs than higher-risk tumor and vascular practices, it may seem counterintuitive that neurosurgeons had more UPCs compared to lower-risk specialties. While the trend of fewer UPCs with more elective procedures may be true within neurosurgery, it may not be true when comparing specialties to one another. For example, lumbar discectomy is a common elective procedure in neurosurgery but may be considered less elective and higher risk than other specialty procedures. Further studies are needed to better understand this discrepancy.

\section{Complaint Types and Ideas for Improvement}

The most common types of complaints in descending order were issues surrounding care and treatment, communication, and accessibility, each of which was significantly higher among neurosurgeons than other surgical specialties. With regard to the care and treatment of patients, there were complaints ranging from inpatient care, such as receipt of home medications, to surgery-related complaints. While some inpatient responsibilities fall to midlevel providers or residents, patients may hold the attending surgeon responsible for all aspects of care. If complaints are arising from systems or service areas not directly under an attending's control, it behooves the attending to seek out the deficiency and help correct it. The surgery-related complaints were mainly attributable to postoperative complications, including reoperation, infection, or continued symptoms after surgery. With respect to communication, some complaints were about patients receiving new information postoperatively, which they claimed to be unaware of preoperatively, further reinforcing the importance of assessing and documenting that patients and family members hear, understand, and recall the procedural details. Some patients were upset with having to wait an extended time for an appointment with the neurosurgeon, only to be further dissatisfied with minimal time spent with the neurosurgeon in clinic. Such perceptions, accurate or not, provide opportunities for neurosurgeons to work with their teams to manage expectations.

While the above complaint types represent systemic issues, some of which are inherent to a busy healthcare system or neurosurgical practice, one area that is outside the bureaucracy is concern for patients. Many patients reported being displeased by a perceived lack of caring or lack of empathy ("He never even came in the room to acknowledge me ... he didn't think enough of me to show his face"). Providing feedback to neurosurgeons who generate 
a disproportionate share of empathy complaints gives opportunities to refine communication styles to optimize the patient's experience. In many cases, these interpersonal corrections generally require only straightforward reflection about alternative interaction skills, and not bureaucratic, time-intensive solutions.

Armed with information about UPCs, the field of neurosurgery can focus on improvement. One intervention among obstetrics and gynecology physicians showed that participation by younger physicians in a psychosocial skills training course was associated with reduced job stress, reduced exhaustion, and improved coping skills. ${ }^{1}$ Other studies provided feedback to physicians who were deemed high risk, and two-thirds of those physicians had significantly fewer patient complaints and sustained those reductions over time. ${ }^{10,15}$ Another study used the Co-worker Observation Reporting System (CORS) to provide feedback in a tiered manner, which would escalate depending on the frequency of reported concerns about behaviors deemed unsafe and/or unprofessional. Coworker reporting requires institutional leadership, reliable processes, and intentionally designed systems supported by a culture that addresses retaliation and fear of retaliation. ${ }^{21}$ Lastly, Boissy et al. ${ }^{22}$ found that 1537 physicians who had undergone communication training versus 1950 who had not had higher performance scores in the areas of empathy and burnout. Improvement will be facilitated by simple awareness of UPC risk, which is up to the individual surgeon, and intervention as needed, which is up to department leaders.

The current UPC data can be cautiously extrapolated to risk of litigation, a consequence with costly and farreaching implications. UPCs have previously been independently associated with malpractice claims. ${ }^{6}$ That said, the threshold for a UPC is much lower than that for a malpractice claim. Demonstrable harm is not required to file a UPC, and no opportunity to defend one's actions exists. In this context, to protect surgeons, departments, and hospitals, it may be beneficial for UPCs to be viewed more as "sentinel events" for future malpractice suits. All involved parties may benefit if UPCs can be taken as a warning of future downstream legal pursuits.

\section{Study Limitations}

This study has several limitations that are worth noting, including the representativeness of our sample and generalizability of our findings. The current sample includes a small number of the country's neurosurgeons, 423 of the approximately 3689 practicing neurosurgeons (11.4\%). ${ }^{23}$ However, to our knowledge, this is the largest study to date of neurosurgical practice and UPCs. In addition, the PARS database has a greater proportion of academic neurosurgeons than has been reported for the general population of neurosurgeons (71\% academic versus private practice breakdown in PARS compared to previously reported national samples, which included $37 \%$ academic). ${ }^{24}$ Academicians are more likely to be subspecialized than those in private practice, who are more likely to operate on an array of pathologies. Moreover, while our study had a disproportionate representation of academic hospitals, one important difference we could not account for was patient treatment in the setting of a private hospital versus a safety-net hos- pital (i.e., with high numbers of uninsured and Medicaid patients). Patients treated at safety-net versus private hospitals have been more likely to be symptomatic from brain metastases, ${ }^{25}$ to have delays to endovascular aneurysm embolization, ${ }^{26}$ and to have increased rates of endocrinopathies after pituitary tumor surgery. ${ }^{27}$ We were unable to account for the presence of safety-net hospitals, which appears to affect the quality of care delivered, and may have downstream effects on patient-physician communication. Along these lines, the current sample's breakdown of specialties differs from that of neurosurgeons throughout the country in the following numbers (our study vs national): functional (10\% vs $2 \%$ ), general practice ( $25 \%$ vs $51 \%$ ), and spine ( $25 \%$ vs $12 \%$ ), whereas similar proportions were seen in pediatrics (10\% vs $8 \%$ ) and tumor $(16 \%$ vs $14 \%){ }^{24}$ Though the relationships between specialty and UPC may still be seen outside of our sample, the proportion of each specialty differed significantly, likely as a result of the academic versus nonacademic affiliations. We also did not account for orthopedic spine providers. While some studies show differences in blood loss and length of stay among orthopedic versus neurosurgery spine providers, ${ }^{28}$ other studies show similar outcomes between both groups. ${ }^{29}$ Our results can technically only be applied to neurosurgery spine providers, which limits our conclusions, and separate studies of both specialties should be conducted.

In addition to concerns regarding the representativeness of the study population, other limitations exist. First, we included only certain variables for each cohort member; we were not able to include case volume and complexity for individual patients or specific operations. The relationship between the volume of surgical cases and the UPC data unfortunately could not be included. It would certainly be helpful to account for the number of patient interactions and the rate of UPCs incurred by each neurosurgeon. Knowing the "denominator" of patient interactions is an important next step in understanding the underlying reasons for UPCs. That said, in prior studies of malpractice risk and complications, inclusion of patient volume in multivariate models did not affect the association between UPCs and the outcomes of interest. ${ }^{6,9}$ Second, to collect specialty data, we relied on public websites, which may be less accurate than surgeon case logs, which were not feasible to collect. To that end, due to concerns over data accuracy we were not able to include board certification status. Third, while the PARS database does not investigate the validity of complaints, all complaints are reviewed by each hospital's Office for Patient Relations. Some UPCs may be unwarranted and unfounded, yet the goal of the PARS database is to collect complaints regardless of merit to provide insight for the physician. Last, because the PARS groups involve many centers, incomplete and heterogenous data collection may exist, though PARS includes benchmarking and data quality checks across all of its sites. ${ }^{10}$

\section{Conclusions}

In this study of unsolicited patient complaints (UPCs) among neurosurgeons, neurosurgeons had more average total complaints and a higher percentage of individuals with at least one complaint than surgeons and nonsurgeon 
physicians of other specialties. Younger age and spine subspecialty were both associated with an increased risk of complaints. The most common complaint types were issues surrounding care and treatment, communication, and accessibility. These results may help the entire neurosurgical field to identify, aggregate, and address complaints in ways designed to improve the overall quality of care delivered.

\section{References}

1. Studdert DM, Mello MM, Sage WM, et al. Defensive medicine among high-risk specialist physicians in a volatile malpractice environment. JAMA. 2005;293(21):2609-2617.

2. Thomas R, Gupta R, Griessenauer CJ, et al. Medical malpractice in neurosurgery: a comprehensive analysis. World Neurosurg. 2018;110:e552-e559.

3. Jena AB, Seabury S, Lakdawalla D, Chandra A. Malpractice risk according to physician specialty. $N$ Engl J Med.2011; 365(7):629-636.

4. Nahed BV, Babu MA, Smith TR, Heary RF. Malpractice liability and defensive medicine: a national survey of neurosurgeons. PLoS One. 2012;7(6):e39237.

5. Balch CM, Oreskovich MR, Dyrbye LN, et al. Personal consequences of malpractice lawsuits on American surgeons. $J$ Am Coll Surg. 2011;213(5):657-667.

6. Cooper WO, Guillamondegui O, Hines OJ, et al. Use of unsolicited patient observations to identify surgeons with increased risk for postoperative complications. JAMA Surg. 2017;152(6):522-529.

7. Hickson GB, Federspiel CF, Blackford J, et al. Patient complaints and malpractice risk in a regional healthcare center. South Med J. 2007;100(8):791-796.

8. Stelfox HT, Gandhi TK, Orav EJ, Gustafson ML. The relation of patient satisfaction with complaints against physicians and malpractice lawsuits. Am J Med. 2005;118(10):1126-1133.

9. Hickson GB, Federspiel CF, Pichert JW, et al. Patient complaints and malpractice risk. JAMA. 2002;287(22):2951-2957.

10. Pichert JW, Moore IN, Karrass J, et al. An intervention model that promotes accountability: peer messengers and patient/ family complaints. Jt Comm J Qual Patient Saf. 2013;39(10): 435-446.

11. Fathy CA, Pichert JW, Domenico H, et al. Association between ophthalmologist age and unsolicited patient complaints. JAMA Ophthalmol. 2018;136(1):61-67.

12. Kohanim S, Sternberg P Jr, Karrass J, et al. Unsolicited patient complaints in ophthalmology: an empirical analysis from a large national database. Ophthalmology. 2016;123(2): 234-241.

13. Hultman CS, Gwyther R, Saou MA, et al. Stuck in a moment: an ex ante analysis of patient complaints in plastic surgery, used to predict malpractice risk profiles, from a large cohort of physicians in the Patient Advocacy Reporting System. Ann Plast Surg. 2015;74(suppl 4):S241-S246.

14. Mukherjee K, Pichert JW, Cornett MB, et al. All trauma surgeons are not created equal: asymmetric distribution of malpractice claims risk. J Trauma. 2010;69(3):549-556.

15. Nassiri AM, Pichert JW, Domenico HJ, et al. Unsolicited patient complaints among otolaryngologists. Otolaryngol Head Neck Surg. 2019;160(5):810-817.

16. Stimson CJ, Pichert JW, Moore IN, et al. Medical malpractice claims risk in urology: an empirical analysis of patient complaint data. J Urol. 2010;183(5):1971-1976.

17. Rolston JD, Han SJ, Lau CY, et al. Frequency and predictors of complications in neurological surgery: national trends from 2006 to 2011. J Neurosurg. 2014;120(3):736-745.

18. Daniels AH, Ruttiman R, Eltorai AEM, et al. Malpractice litigation following spine surgery. J Neurosurg Spine. 2017; 27(4):470-475.
19. Taylor CL. Neurosurgical practice liability: relative risk by procedure type. Neurosurgery. 2014;75(6):609-613.

20. Kessler RA, Benzil DL, Loewenstern J, et al. Malpractice litigation in brain tumor surgery: a 31-year analysis of causative factors in the United States from the Westlaw database. World Neurosurg. 2019;122:e1570-e1577.

21. Webb LE, Dmochowski RR, Moore IN, et al. Using coworker observations to promote accountability for disrespectful and unsafe behaviors by physicians and advanced practice professionals. Jt Comm J Qual Patient Saf. 2016;42(4):149-164.

22. Boissy A, Windover AK, Bokar D, et al. Communication skills training for physicians improves patient satisfaction. $J$ Gen Intern Med. 2016;31(7):755-761.

23. Statement of the American Association of Neurological Surgeons, American Board of Neurological Surgery, Congress of Neurological Surgeons, and the Society of Neurological Surgeons before the Institute of Medicine. Ensuring an Adequate Neurosurgical Workforce for the 21st Century. 2012. Accessed May 21, 2020. https://www.cns.org/sites/default/ files/legislative/NeurosurgeryIOMGMEPaper121912.pdf

24. Rosman J, Slane S, Dery B, et al. Is there a shortage of neurosurgeons in the United States? Neurosurgery. 2013;73(2): 354-355, 365-366.

25. Diao K, Sun Y, Yoo SK, et al. Safety-net versus private hospital setting for brain metastasis patients treated with radiosurgery alone: disparities in follow-up care and outcomes. Cancer. 2018;124(1):167-175.

26. Donoho DA, Patel A, Buchanan IA, et al. Treatment at safetynet hospitals is associated with delays in coil embolization in patients with subarachnoid hemorrhage. World Neurosurg. 2018;120:e434-e439.

27. Cyprich J, Pangal DJ, Rutkowski M, et al. Comparative preoperative characteristics and postoperative outcomes at a private versus a safety-net hospital following endoscopic endonasal transsphenoidal resection of pituitary adenomas. $J$ Neurosurg. Published online February 28, 2020. doi: 10.3171/2019.12.JNS192506

28. Seicean A, Alan N, Seicean S, et al. Surgeon specialty and outcomes after elective spine surgery. Spine (Phila Pa 1976). 2014;39(19):1605-1613.

29. Mabud T, Norden J, Veeravagu A, et al. Complications, readmissions, and revisions for spine procedures performed by orthopedic surgeons versus neurosurgeons: a retrospective, longitudinal study. Clin Spine Surg. 2017;30(10):E1376-E1381.

\section{Disclosures}

The authors report no conflict of interest concerning the materials or methods used in this study or the findings specified in this paper.

\section{Author Contributions}

Conception and design: Zuckerman, Thompson, Galloway, Pichert, Cooper. Acquisition of data: Zuckerman, Dambrino, Guidry, Domenico, Galloway. Analysis and interpretation of data: Zuckerman, Dambrino, Domenico. Drafting the article: Zuckerman, Dambrino. Critically revising the article: Zuckerman, Dambrino, Pichert, Cooper. Reviewed submitted version of manuscript: Zuckerman, Thompson, Galloway, Pichert, Cooper. Approved the final version of the manuscript on behalf of all authors: Zuckerman. Statistical analysis: Guidry, Domenico, Galloway. Administrative/technical/material support: Thompson, Pichert, Cooper. Study supervision: Thompson, Pichert, Cooper.

\section{Correspondence}

Scott L. Zuckerman: Vanderbilt University Medical Center, Nashville, TN. zuckerman.scott@gmail.com. 